\title{
Monitoring and Application of Artificial Neural Network Model for Prediction of Organophosphorus Pesticides Residue in Ahvaz Water Treatment Plants
}

\author{
Mehdi Ahmadi ${ }^{1,2}(\mathbb{D})$, Sahand Jorfi ${ }^{1,2}(\mathbb{D})$, Yaser Tahmasebi Birgani ${ }^{1,2} * \mathbb{D}$, Zeinab Ghaedrahmat ${ }^{3,4}$ * \\ Department of Environmental Health Engineering, Ahvaz Jundishapur University of Medical Sciences, Iran \\ Environmental Technologies Research Center, Ahvaz Jundishapur University of Medical Sciences, Ahvaz, Iran; \\ Student Research Committee, Department of Environmental Health Engineering, Ahvaz Jundishapur University of \\ Medical Sciences, Ahvaz, Iran \\ 4 Department of Environmental Health Engineering, Shoushtar Faculty of Medical Sciences, Shoushtar, Iran \\ * Correspondence: Z_rahmati4007@yahoo.com;
}

Scopus Author ID 2846129

Received: 26.01.2021; Revised: 20.02.2021; Accepted: 23.02.2021; Published: 2.03.2021

\begin{abstract}
Organophosphorus pesticides are the largest and most diverse pesticides. The overuse of pesticides will cause them to remain in the food, water, soil, and air, hazardous to human health. This study was conducted in three seasons to determine organophosphorus pesticide concentration. The experiments were modeled using artificial neural networks. The results showed that parathion, malathion, and diazinon concentrations were significantly different $(p<0.05)$. The most concentrations were observed in Aug, September, and October. The OPPs concentration in water treatment plants' effluents indicated that concentrations of pesticides were below the maximum contaminant level. Base on the results of an artificial neural network, the model performance to be the best prediction for malathion concentration in the WTP (NO.1), with 6 neurons with $\mathrm{R}^{2}=0.887$, parathion with 5 neurons and $\mathrm{R}^{2}=0.711$, and diazinon with 11 neurons and $\mathrm{R}^{2}=0.714$. The finding of ANN modeling for malathion concentration in the WTP (NO.2), with 9 neurons and $\mathrm{R}^{2}=0.713$, parathion, one hidden layer with 6 neurons and $R^{2}=0.71$, and parathion with 15 neurons and $R^{2}=0.674$ were showed the best prediction.
\end{abstract}

Keywords: artificial neural network; Karun river; organophosphorus pesticide; water treatment plant.

(C) 2021 by the authors. This article is an open-access article distributed under the terms and conditions of the Creative Commons Attribution (CC BY) license (https://creativecommons.org/licenses/by/4.0/).

\section{Introduction}

The Pesticides used in agriculture can enter surface water sources through irrigation and rainfall and cause pollution of these waters, which can also have adverse effects indirectly through agricultural products and entry into the food chain [1-4]. Nervous gastrointestinal disorders and endocrine disorders are among the adverse effects of emerging organic compounds, herbicides, and organic toxins [5-8]. Organophosphorus toxins are considered a serious threat to human health due to their effect on the enzyme cholinesterase activity and disarrangement for the central nervous system. According to global statistics, the highest mortality due to pesticides is related to organophosphorus pesticides. Among the phosphorus pesticides, parathion, malathion, and diazinon are used by farmers due to their effect on a wide range of pests and low cost than other pesticides [6].

The overuse of pesticides will cause them to remain in the food, water, soil, and air, hazardous to human health. Therefore, international forums (World Health Organization and 
United Nation Food and Agriculture Organization) formulate a list of Acceptable Daily Intake (ADI) and Maximum Residue Limit (MRL) to reduce harmful exposure to these substances [9]. The permissible limits for parathion, malathion, and diazinon are $0.1 \mathrm{mg} \mathrm{m}^{-3}, 1 \mathrm{mg} \mathrm{m}^{-3}$, and $0.01 \mathrm{mg} \mathrm{m}^{-3}$, respectively [6]. Modeling the inlet and outlet of the treatment plant is essential for the prediction of treatment plant output. Moreover, certain critical process parameters cannot be measured online, so it is hard to recognize and address troublesome circumstances quickly; therefore, it is challenging to model treatment plant flows, and most current models are estimated based on assumptions. These features make it difficult to achieve the treatment plant production efficiency using traditional methods for modeling. Therefore, advanced modeling techniques need to be developed to forecast treatment plant production. Neural networks have also been found to be promising techniques in historical data predicting.

Artificial neural networks (ANN) are achievements that can be used to model complex and unknown phenomena by modeling the human brain network [10-15]. Neural networks are made up of simple units called neurons and provide cells similar to those found in the human brain. In a network, neurons are acquired by weight connections. By adjusting these weights, the process of learning within the network is achieved. The neural network including a set of layers. The first layer containing the input data, and the last layer is containing the output data. The underside layers fit between the inlet and outlet layers. Neural networks can be monolayer or multilayer. The process of analyzing the data starts with the input parameters to the first layer of neurons, and then the data propagates to the second layer neurons for further adjustments. The results are then transmitted to the next layer, and this process continues to reach the output data layer $[14,16,17]$. As one of the agricultural and industrial areas, including oil, gas and petrochemicals and steel industries, the province of Khuzestan contributes to mass production and discharge in various ways. The many fertile agricultural lands throughout the province are also a major source of consumption and disposal of herbicides, pesticides, and organic matter. Since one of the final destinations for many of these compounds is the province's surface water resources, on the other hand, the source of drinking water supply for a significant part of the urban population is the surface water resources of Khuzestan province. So, monitoring and tracking these compounds in the catchment and outlet of Khuzestan water treatment plants (WTPs) are very important.

\section{Materials and Methods}

\subsection{Chemicals.}

Three organophosphorus pesticides (OPPs) have been used in this study, which contains parathion, malathion, diazinon, which were analytical grade and purchased from Sigma-Aldrich. The acetone, dichloromethane, de-ionized water, and methanol were analytical grade and purchased from Sigma-Aldrich. Methanol was used to prepare Stoke standard solutions. It should be noted that this solution was stored at $4{ }^{\circ} \mathrm{C}$ to prevent degradation.

\subsection{Sample collection.}

A period of seven months in 2019 was used for sampling from inlet and effluent of the WTPs (No. 1 and 2 in Ahvaz city), which receive their raw water from Karun River. This study was carried out in three seasons (winter of 2018 and autumn and summer of 2019) (August, September, October, November, December, January, February). The weekly sampling had been carried out to determine parathion, malathion, and diazinon concentration. The samples 
were gathered from $10 \mathrm{~cm}$ beneath the water surface in $2.5 \mathrm{~L}$ of glass bottles, topped off to the seal,, and put away at $4{ }^{\circ} \mathrm{C}$ in dull until the investigation because drainage of sugarcane industry enters the Karun River and phosphorus pesticides are used in this industry. The sampling period of 7 months in this study was done before, during, and after cultivation season.

\subsection{Extraction of OPPs residues.}

Liquid extraction technique (DLLME) was used to extract pesticides [18, 19]. The separation was performed using a polypropylene cartridge column with one gram of silica gel that had previously been incubated at $130^{\circ} \mathrm{C}$ for $10 \mathrm{~h}$. Then $20 \mathrm{~mL}$ of dichloromethane was used for the column cartridge washing process. The samples were concentrated using a rotary evaporator (Buchi Rotavapor R-210, USA) at a temperature of $40^{\circ} \mathrm{C}$. The residual sample was resuspended in $1 \mathrm{~mL}$ of ethyl acetate and was a move to vials of $2 \mathrm{~mL}$, and the sample was prepared for injection. The gas chromatograph conditions were used in this study as follows: injection temperature of $220^{\circ} \mathrm{C}$, the gas pressure of $60 \mathrm{PSI}$, column temperature of $190{ }^{\circ} \mathrm{C}$, detector temperature of $270^{\circ} \mathrm{C}$, nitrogen gas velocity $30 \mathrm{~mL} \mathrm{~min}^{-1}$, column length $200 \mathrm{~cm}$, inner diameter $2 \mathrm{~mm}$. All analyses were carried out with a Gas Chromatography-Mass Spectrometer system (GC Agilent 7890 and MS Agilent 5975, USA). To assess the affectability of the DLLME and GC-MS method for analysis of OPPs, the estimations of Limit of Detection (LOD) and Limit of Quantitation (LOQ) were calculated for each analyte. The LODs for parathion, malathion, and diazinon were 10.9, 39.6, and $1.6\left(\mathrm{ng} \mathrm{L}^{-1}\right)$, respectively, and the LOQs for the mentioned analytes were $35.1,132.4$, and $5.7\left(\mathrm{ng} \mathrm{L}^{-1}\right)$.

\subsection{Artificial neural networks (ANN) modeling.}

ANNs are numerical models comprising straightforward, thickly interconnected components known as neurons, normally orchestrated in a layer. The ANN model's main practice is to plan a group of inputs to a group of outputs. The approaching signs are imitated by relative loads through which they are circulated concerning neurons or node, where they are aggregated (summarized). Accordingly, the net info is talented the initiation capacity to gracefully the output. The output of every node is obtained by registering the estimation of the enactment work for the result of the information vector and the weight vector in addition to the estimation of the inclination identified with the node. Mathematically this can be represented as Equation 1 [20].

$$
Y=f\left(\sum_{i=1}^{N} w i . x i+b\right)
$$

Where, $x i(i=1,2, \ldots n)$ are inputs and wi $(i=1,2, \ldots n)$ are respective weights, $b$ is the bias, $y$ is the output and $f($.$) is the activation function. The net contribution to the node can be$ communicated as Equation 2 [20]:

$$
\text { net }=\sum_{i=1}^{n} x_{i} w_{i}
$$

Artificial neural networks (ANNs) have been utilized in various domains for modeling and prediction with high accuracy due to their ability to learn and adapt [17, 21]. The first practical application of artificial neural networks was performed by Rosenblatt [22] to introduce multilayer perceptron (MLP). Multilayer perceptron (MLP) comprises input, hidden, and output layers, which are considered neurons in each layer's network architecture. The quantity of neurons in the input and output layers is controlled by the idea of the issue under study, while the number of neurons in the hidden layers as well as the quantity of these layers by trying and errors to reduce the amount of error. In this study, for modeling the phosphorus 
pesticides concentration in the treatment plant effluent using MLP model, one hidden layer with different neurons and sigmoid function boundary stimulus functions and different training methods were used. The post-propagation error method with the Levenberg-Marquardt algorithm has been used for faster convergence in network training. In this study, the experiments were modeled using artificial neural networks.

The attributed data are included one input (Intel OPPs concentration of treatment plant ( Number1 and Number 2)) and 6 output attributes (Outlet OPPs concentration of both treatment plant). Fig. 1 illustrates the structure of a multilayer perceptron with one output and one hidden layer. The calculation of ANN was performed using MATLAB.

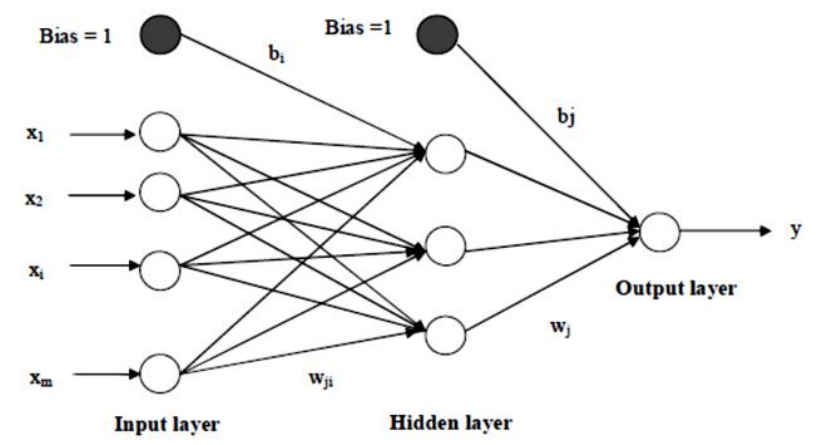

Figure 1. Network structure of multilayer perceptron with one output and one hidden layer.

\subsection{Statistical analysis.}

All data were analyzed utilizing Excel, SPSS v.23 software for windows. Descriptive statistics such as means, standard deviation, max, and min values were assessed first. The normality of data was checked utilizing the Kolmogorov-Smirnov test (significance value was weighed as $P$ value $\leq 0.05)$ [23].

\section{Results and Discussion}

\subsection{OPPs concentration.}

The distribution of OPPs concentration in the intakes of WTPs from Karun River during the sampling period was presented in Fig. 2.

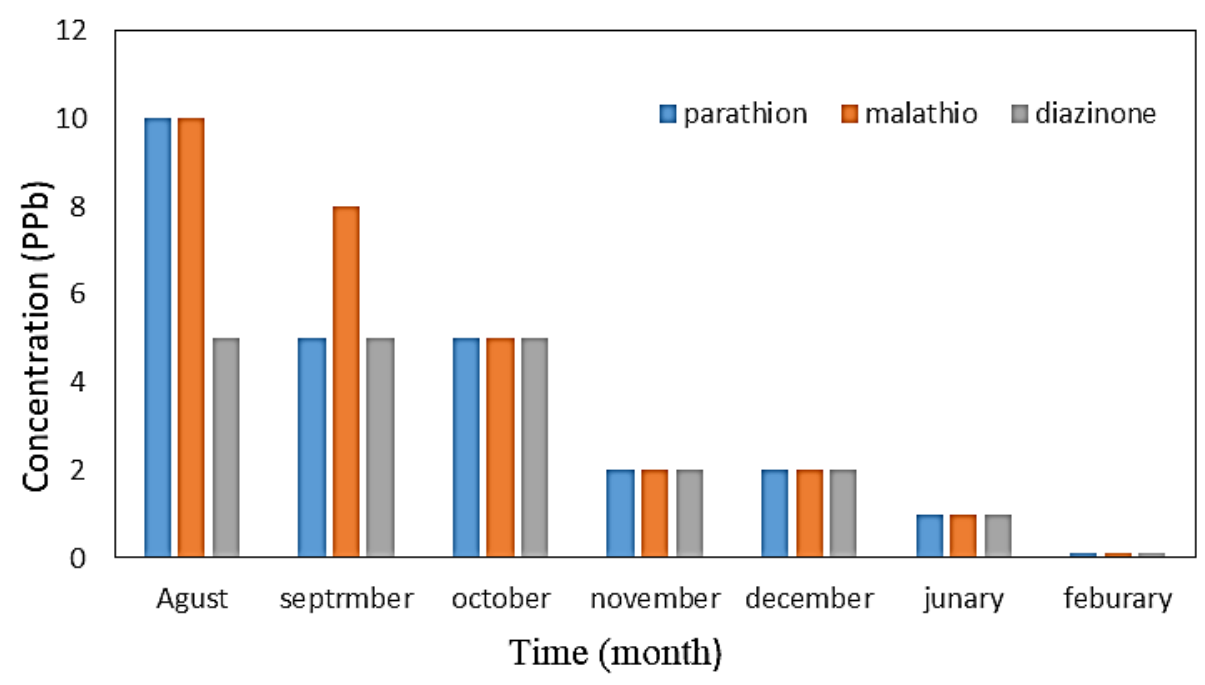

Figure 2. Variations of OPPs concentration vs. the time in Karun River. 
The results of comparing the mean concentrations of pesticides in different months using the analysis of variance test with repeated measures showed that the concentrations of parathion, malathion, and diazinon during seven months significantly different $(p<0.05)$. The mean concentration of pesticide in surface water sample was exceeded from European Union maximum residue limit (MLR) of $1 \mu \mathrm{g} \mathrm{L}^{-1}$ for total pesticide in surface water [24] and within range of MRL of WHO [25].

As can be seen, the most concentrations were observed in Aug, September, and October. The remaining months were showed almost similar concentrations. These months are mostly corresponding to the time during and after the cultivation period. The washout of applied pesticides resulted in increased OPPs concentrations in water resources. Precipitation is another factor affecting water pollution because of the high rainfall level that increases pesticide pollution risk. The transmission of pesticides in water resources is directly followed by using these compounds for target regions in drains after the rain. The soil structure change also occurs by shifting pesticides from the absorption site by water and soil that has been transferred into water by soil erosion because rain washes and discharges freshly applied pesticides into water sources, coincident with the irrigation period in Khuzestan province farms. These findings may be attributed to decreased river water volume, reduced rainfall, and increased temperature in the summer [13, 26, 27]. It should be mentioned that these pesticides are often used in autumn and summer in Khuzestan province.

Organophosphate pesticides are used by farmers more than other pesticides due to their wide range of applications and low cost. Also, field results show that most farmers do not take the necessary precautions in using pesticides, and this practice has led to the spread of pesticiderelated diseases in these agricultural areas.

Some previous study studies are inconsistent with the present study and OPPswas more than MRLs of WHO [24, 28, 29]. The presence of pesticides in water sources can be due to the movement of toxins from agricultural lands to water sources, regional runoff, and soil leakage [30]. The residual concentration of pesticides in water resources depends on a different parameter such as water temperature, hydrolysis, the phenomenon of adsorption of pesticides by organic matter in soil and water, the number of solutes in water, the proximity of water resources and agricultural lands [31], hence the residual concentrations of organic phosphorus toxins in different sources are different from each other. In another study, it was found that the residual concentrations of diazinon and malathion were higher than the permitted values up to one month after spraying, but the residual pesticides decreased to zero after two to three months [32]. A previous study that investigated pesticide residues in California surface waters showed that $92 \%$ of the samples contained one or more pesticides, some of which had higher than standard diazinon values [33]. The results of this study were in consistent with the results of the present study. The difference in the amount of insecticide was related to pesticides consumed by farmers. Also, the low price of pesticides is not ineffective in the overuse of pesticides in Kermanshah province. Factors such as population increase, food shortages, and the occurrence of various diseases of agricultural products have caused farmers to resort to the use of fertilizers and pesticides. Increasing farmers' awareness and scientific performance following the latest scientific principles and correct crop cultivation concerning the amount of pesticide consumption, how to use, and frequency of use in agricultural lands can prevent the excessive entry of agricultural pesticides into soil and water resources.

The results of OPPs concentration in the effluents of WTPs indicated that the concentrations of pesticides were below the maximum contaminant level (Table 1). The high 
removal of OPPs and zero discharge could be attributed to chemical agents' application in the coagulation unit, oxidants, sand filtration, and activated carbon column [34]. However, some of the pesticides were observed in the post-treatment stage. It is essential to mention that many of these OPPs were eliminated numerous years ago and their existence in water-sediment due to prior utility and persistent nature of these compounds. Also, the results of OPPs concentration in effluent indicated that was nothing observed in January, February. The Karun River flow rate is high during the winter and autumn months, so it increased the mixing of water with air and dissolved oxygen levels. The increasing amount of dissolved oxygen in the water leads to a reduction in microbial contamination and the concentration of other chemical pollutants causing a possible pesticide reaction in the river water with oxygen, resulting in the oxidation and change in the pesticide structure, or its destruction [35].

Table 1. Concentration of OPPs in the inlet of water WTP of NO.1 and 2 Ahvaz.

\begin{tabular}{l|c|c|c|c|c} 
OPPs $\left(\boldsymbol{\mu} \mathbf{g L}^{-\mathbf{1}}\right)$ & $\mathbf{N}$ & Minimum & Maximum & Mean & Std. Deviation \\
\hline Intel of WTPs & & & & & \\
\hline Parathion & 7 & 0.10 & 10.00 & 3.5857 & 3.39138 \\
\hline Malathion & 7 & 0.10 & 10.00 & 4.0143 & 3.76848 \\
\hline Diazinon & 7 & 0.10 & 5.00 & 2.8714 & 2.09341 \\
\hline Outlet of WTPs NO.1 & & & & & \\
\hline Parathion & 7 & 0.00 & 0.07 & 0.0371 & 0.02870 \\
\hline Malathion & 7 & 0.00 & 0.09 & 0.0500 & 0.03606 \\
\hline Diazinon & 7 & 0.00 & 0.08 & 0.0443 & 0.03207 \\
\hline Outlet of WTPs NO.2 & & & & & \\
\hline Parathion & 7 & 0.00 & 0.09 & 0.0414 & 0.03436 \\
\hline Malathion & 7 & 0.00 & 0.09 & 0.0514 & 0.03716 \\
\hline Diazinon & 7 & 0.00 & 0.09 & 0.0486 & 0.03579
\end{tabular}

\subsection{ANN model results.}

One of the most fundamental artificial neural models available is the Multi-Layer Perceptron (MLP) model, which imitates the human brain's transfer function. In this type of neural network, most of the behavior of human brain networks and signal propagation has been considered, and hence, they are sometimes referred to as feed-forward networks. Each neuron in the human brain, called a neuron, processes input (from another neuron or non-neuron) and transmitted the result to another cell (neuron or non-neuron). This behavior continues until a definite output is reached, which is likely to eventually led to a decision, process, thought, or move $[27,36]$.

, The amount of neurons in the hidden layer is primarily liable for correlation between different input and output considered in building up an MLP ANN. The best system for choosing the best possible number and size (s) of the hidden layer(s) is experimentation. Thus, the hidden layer becomes very important in MLP-ANN modeling, and it will result in better efficiency and comparatively less training of the network [37]. In this study, a feed-forward MLP model with one hidden layer was used to predict OPPs concentration. An experimentation framework was utilized to determine the optimal neuron number concerning MSE decrease to minimize the error. Each trial with MLP (test and train) was done multiple times (7run), and we obtain the mean estimations of the error to contemplate the relationship between indicators and execution. In training data, the RSME decreases with the increased number of neurons in the hidden layer. As the number of neurons increases, the RSME in the test data increases. This increase is a sign of the over-training of neural networks. If the number of neurons increases from a certain level, the neural network will retain the data instead of training. So, the RMSE 
in the training data will decrease. According to this process, the optimal number of neurons was selected.

In the process of designing and training an artificial neural network, the accuracy of the intra-loop network is developed, which values the weights and biases to achieve optimal values in terms of $\mathrm{R}^{2}$ and MSE. Neural network testing is usually performed in two stages of calling and generalization to evaluate its performance in predicting outputs. In the call phase, the data sets are applied to train the network for evaluate network performance. In the generalization phase, network performance is evaluated using new data sets. In the call phase, during the training process, the network performance is checked against the actual data [13, 38].

The high value of $\mathrm{R}^{2}$ indicates the ability of the model to predict the concentration of OPPs. The models generated by neural networks within the defined range predict the concentration of OPPs. This model will not work well for data outside the defined range. In this study, the numbers of neurons in the hidden layer have been considered in the range varying from 5 to 15 , satisfying all the criteria as the number of one input and 6 output. In this way, 12 model network architectures were attempted to select the best model architecture for MLP. The comparison between actual and predicted data for OPPs concentration is indicated in Fig. 3-8. Base on the results of an artificial neural network, the model performance was found to be the best prediction for malathion concentration in the WTP (NO.1) of Ahvaz (Fig. 3), with 6 neurons with $\mathrm{R}^{2}=0.887$, parathion (Fig. 4) with 5 neurons and $\mathrm{R}^{2}=0.711$ and diazinon (Fig. 5) with 11 neurons and $\mathrm{R}^{2}=0.714$.

The finding of ANN modeling for malathion concentration in the WTP (NO.2) (Fig. 6), with 9 neurons and $\mathrm{R}^{2}=0.713$, parathion (Fig. 7), one hidden layer with 6 neurons and $\mathrm{R}^{2}=$ 0.71 , and parathion (Fig. 8) with 15 neurons and $\mathrm{R}^{2}=0.674$ were showed the best prediction. The results of the ANN model for various numbers of neurons were indicated in Fig. 9. In this study, the minimum RMSE of 1.66 was achieved for malathion in WTP (NO.1). The results of artificial neural network modeling for OPPs concentration after treatment showed that the model could predict the concentration of OPPs after treatment, and the model for malathion was showed the best prediction in the both WTPs of Ahvaz. In the previous study was reported that ANN model had the option to forecast the effluent wastewater quality with a correlation efficiency of 0.97 [16]. Another study was found that ANN model developed forecasting of the effluent. [39] Another study was applied the ANN model to predict the effluent WTP performance in dairy industry. It was investigated that, ANN model provides an effective analysis to comprehend and imitate the non-linear manner of the WTP [12, 40-42].
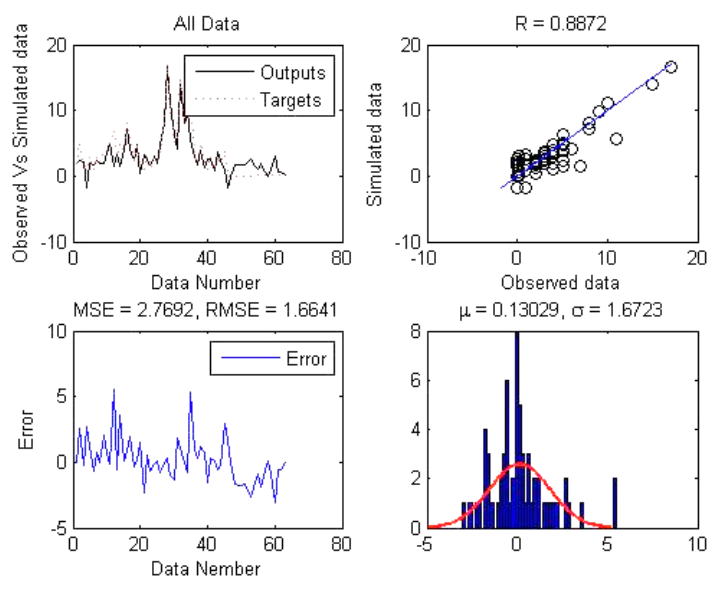

Figure 3. Prediction of malathion concentration in WTP of NO.1 

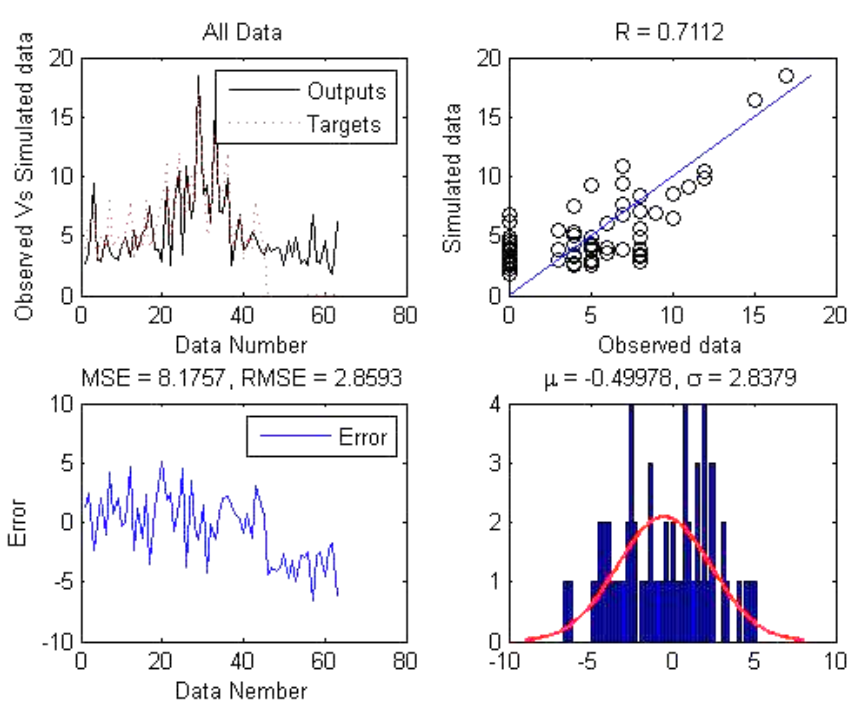

Figure 4. Prediction of malathion concentration in WTP of NO.1.
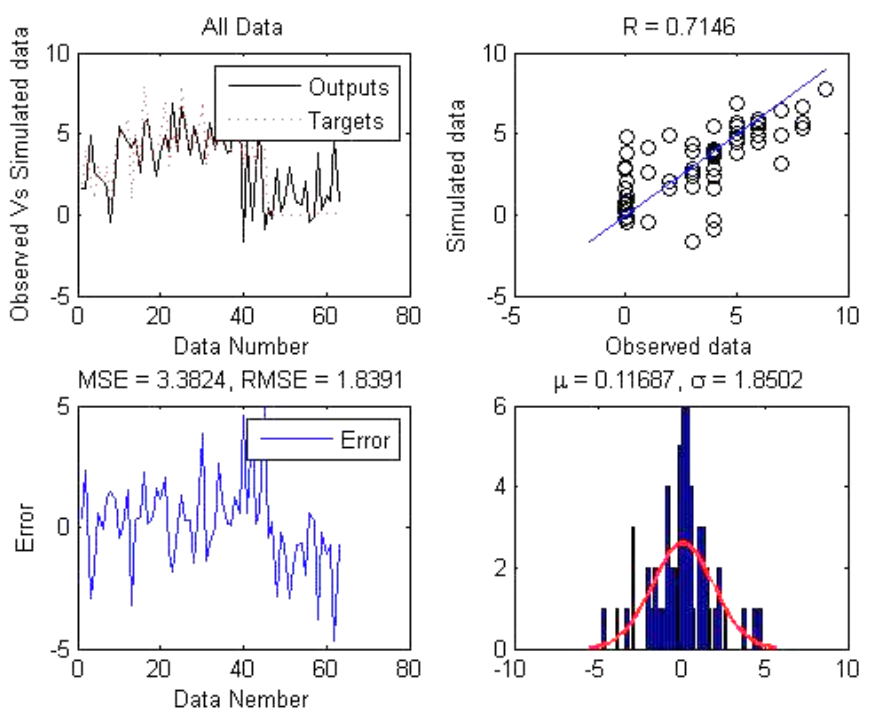

Figure 5. Prediction of diazinon concentration in WTP of NO.1.
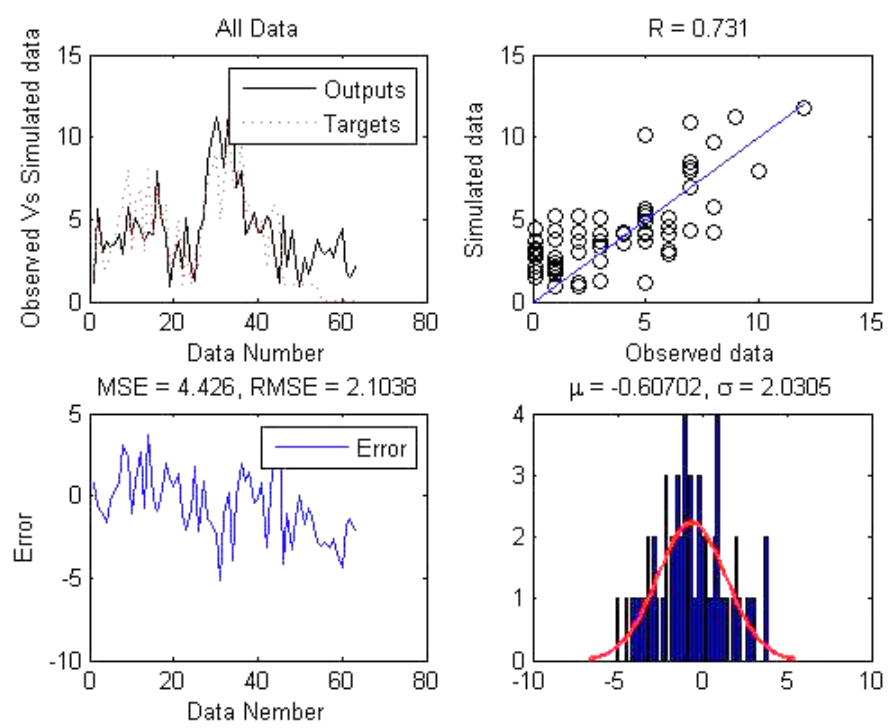

Figure 6. Prediction of malathion concentration in WTP of NO.2. 

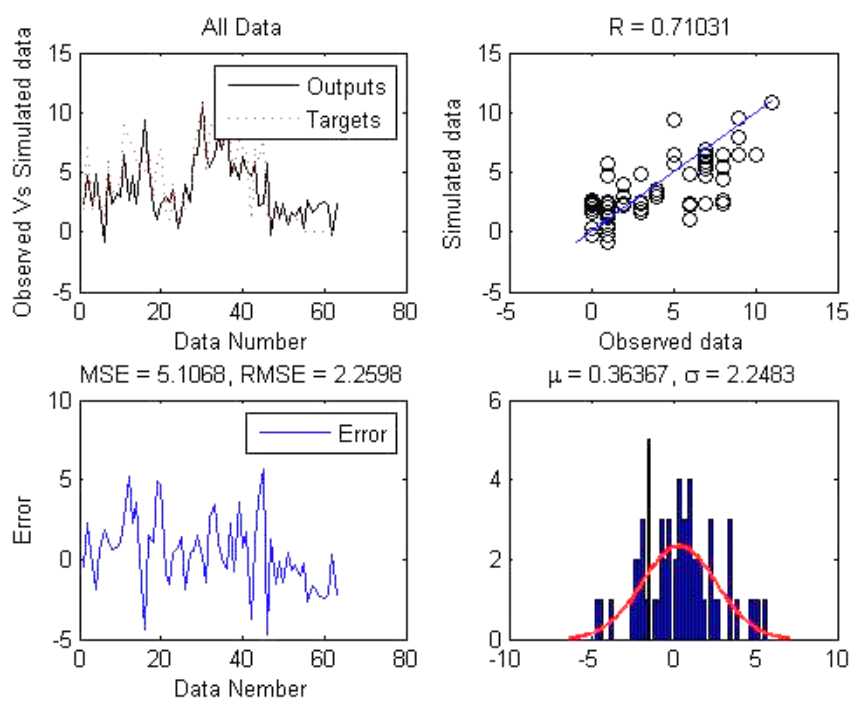

Figure 7. Prediction of parathion concentration in WTP of NO.2.
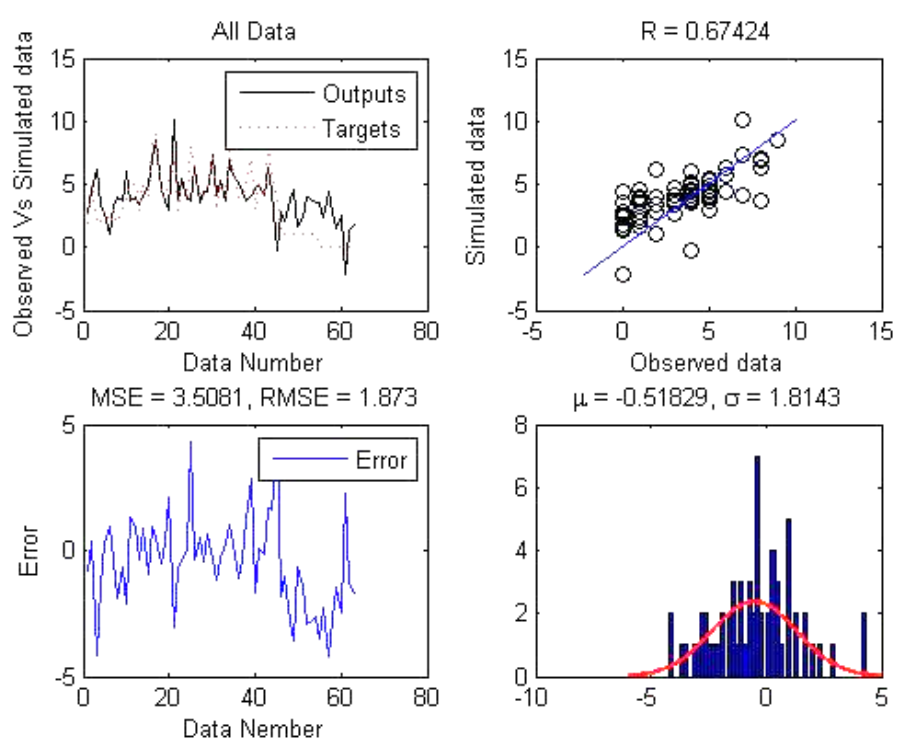

Figure 8. Prediction of diazinon concentration in WTP of NO.2.
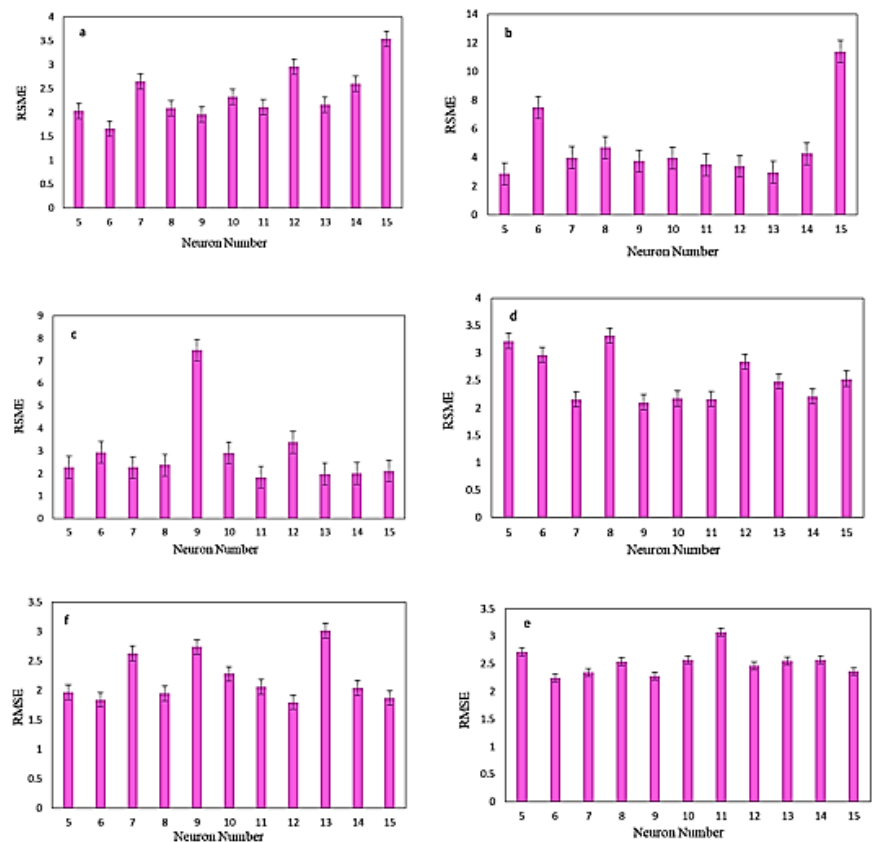

Figure 9. The consequences of test and train the ANN model with a various number of neurons. 


\section{Conclusions}

In this study, organophosphorus pesticide residue was investigated in Ahvaz water treatment plant. The mean concentration of pesticide in surface water sample was exceeded from European Union maximum residue limit (MLR) of $1 \mu \mathrm{g} \mathrm{L}^{-1}$ for total pesticide in surface water and within range of MRL of WHO guideline for pesticide. The results of OPPs concentration in the effluents of water treatment plants indicated that the concentrations of pesticides were below the maximum contaminant level. The results of artificial neural network modeling for OPPs concentration after treatment were showed that the model was able to predict the concentration of OPPs after treatment. The ANN model for malathion was showed the best prediction in both WTPs.

\section{Funding}

This research did not receive any specific grant from funding agencies in the public, commercial, or not-for-profit sectors.

\section{Acknowledgments}

This research project has been financially supported by the Research Department at Ahvaz Jundishapur University of Medical Sciences (No. 97s35).

\section{Conflicts of Interest}

The authors declare no conflict of interest.

\section{References}

1. Derbalah, A.; Ismail, A.; Shaheen, S. Monitoring of organophosphorus pesticides and remediation technologies of the frequently detected compound (chlorpyrifos) in drinking water. Polish Journal of Chemical Technology 2013, 15, 25-34, https://doi.org/10.2478/pjct-2013-0040.

2. Masiá, A.; Campo, J.; Navarro-Ortega, A.; Barceló, D.; Picó, Y. Pesticide monitoring in the basin of Llobregat River (Catalonia, Spain) and comparison with historical data. Science of the Total Environment 2015, 503-504, 58-68, https://doi.org/10.1016/j.scitotenv.2014.06.095.

3. Wee, S.Y.; Aris, A.Z. Ecological risk estimation of organophosphorus pesticides in riverine ecosystems. Chemosphere 2017, 188, 575-581, https://doi.org/10.1016/j.chemosphere.2017.09.035.

4. Wu, J.Y.; Zhang, H.X.; Peng, X.T. Rapid determination of organophosphorus pesticides in edible vegetable oils by direct microextraction using magnetic mesoporous silica microspheres. Separation Science Plus 2020, 3, 158-166, https://doi.org/10.1002/sscp.201900095.

5. McKinlay, R.; Plant, J.; Bell, J.; Voulvoulis, N. Endocrine disrupting pesticides: implications for risk assessment. Environment international 2008, 34, 168-183, https://doi.org/10.1016/j.envint.2007.07.013.

6. Nollet, L.M.; Rathore, H.S. Handbook of pesticides: methods of pesticide residues analysis. CRC press: 2016.

7. Amiri, A.; Tayebee, R.; Abdar, A.; Sani, F.N. Synthesis of a zinc-based metal-organic framework with histamine as an organic linker for the dispersive solid-phase extraction of organophosphorus pesticides in water and fruit juice samples. Journal of Chromatography A 2019, 1597, 39-45, https://doi.org/10.1016/j.chroma.2019.03.039.

8. Kaur, R.; Kaur, R.; Rani, S.; Malik, A.K.; Kabir, A.; Furton, K.G. Application of fabric phase sorptive extraction with gas chromatography and mass spectrometry for the determination of organophosphorus pesticides in selected vegetable samples. Journal of separation science 2019, 42, 862-870, https://doi.org/10.1002/jssc.201800854.

9. Wagner, C.H.; Cox, M.; Robles, J.L.B. Pesticide lock-in in small scale Peruvian agriculture. Ecological Economics 2016, 129, 72-81, https://doi.org/10.1016/j.ecolecon.2016.05.013.

10. Ghaedrahmat, Z.; Vosoughi, M.; Birgani, Y.T.; Neisi, A.; Goudarzi, G.; Takdastan, A. Prediction of O 3 in the respiratory system of children using the artificial neural network model and with selection of input based on gamma test, Ahvaz, Iran. Environmental Science and Pollution Research 2019, 26, 10941-10950, https://doi.org/10.1007/s11356-019-04389-7. 
11. Li, L.; Jiang, P.; Xu, H.; Lin, G.; Guo, D.; Wu, H. Water quality prediction based on recurrent neural network and improved evidence theory: a case study of Qiantang River, China. Environmental Science and Pollution Research 2019, 26, 19879-19896, https://doi.org/10.1007/s11356-019-05116-y.

12. Zhang, L.; Zou, Z.; Shan, W. Development of a method for comprehensive water quality forecasting and its application in Miyun reservoir of Beijing, China. Journal of Environmental Sciences 2017, 56, 240-246, https://doi.org/10.1016/j.jes.2016.07.017.

13. Zhai, W.; Zhou, X.; Man, J.; Xu, Q.; Jiang, Q.; Yang, Z.; Jiang, L.; Gao, Z.; Yuan, Y.; Gao, W. Prediction of water quality based on artificial neural network with grey theory. IOP Conference Series: Earth and Environmental Science 2019, 295, https://doi.org/10.1088/1755-1315/295/4/042009.

14. Lim, H.; An, H.; Kim, H.; Lee, J. Prediction of pollution loads in the Geum River upstream using the recurrent neural network algorithm. Korean Journal of Agricultural Science 2019, 46, 67-78, https://doi.org/10.7744/kjoas.20180085.

15. Csábrági, A.; Molnár, S.; Tanos, P.; Kovács, J.; Molnár, M.; Szabó, I.; Hatvani, I.G. Estimation of dissolved oxygen in riverine ecosystems: Comparison of differently optimized neural networks. Ecological Engineering 2019, 138, 298-309, https://doi.org/10.1016/j.ecoleng.2019.07.023.

16. Priya, K.; Abbasi, T.; Murugaiyan, V. Modeling the performance of a tannery common effluent treatment plant using artificial neural networks. Desalination And Water Treatment 2018, 122, 57-65, https://doi.org/10.5004/DWT.2018.22669.

17. Sinshaw, T.A.; Surbeck, C.Q.; Yasarer, H.; Najjar, Y. Artificial neural network for prediction of total nitrogen and phosphorus in US Lakes. Journal of Environmental Engineering 2019, 145, https://doi.org/10.1061/\%28ASCE\%29EE.1943-7870.0001528.

18. Chahkandi, M.; Amiri, A.; Arami, S.R.S. Extraction and preconcentration of organophosphorus pesticides from water samples and fruit juices utilizing hydroxyapatite/Fe3O4 nanocomposite. Microchemical Journal 2019, 144, 261-269, https://doi.org/10.1016/j.microc.2018.09.018.

19. Medina, D.A.V.; Cabal, L.F.R.; Lanças, F.M.; Santos-Neto, Á.J. Sample treatment platform for automated integration of microextraction techniques and liquid chromatography analysis. HardwareX 2019, 5, https://doi.org/10.1016/j.ohx.2019.e00056.

20. Patil, S.; Valunjkar, S. Farecasting of daily runoff using artificial neural networks. International Journal of Civil Engineering and Technology 2014, 0976-6308.

21. Haykin, S. Neural networks: a comprehensive foundation. Prentice Hall PTR: 1994.

22. Rosenblatt, F. The perceptron: a probabilistic model for information storage and organization in the brain. Psychological review 1958, 65.

23. Myers, L.; Sirois, M.J. Spearman correlation coefficients, differences between. Encyclopedia of statistical sciences 2004, 12, https://doi.org/10.1002/0471667196.ess5050.

24. Lari, S.Z.; Khan, N.A.; Gandhi, K.N.; Meshram, T.S.; Thacker, N.P. Comparison of pesticide residues in surface water and ground water of agriculture intensive areas. Journal of Environmental Health Science and Engineering 2014, 12, https://doi.org/10.1186/2052-336X-12-11.

25. Edition, F. Guidelines for drinking-water quality. WHO chronicle 2011, 38, 104-108.

26. Corsolini, S.; Ademollo, N.; Romeo, T.; Greco, S.; Focardi, S. Persistent organic pollutants in edible fish: a human and environmental health problem. Microchemical Journal 2005, 79, 115-123, https://doi.org/10.1016/j.microc.2004.10.006.

27. Cabaneros, S.M.; Calautit, J.K.; Hughes, B.R. A review of artificial neural network models for ambient air pollution prediction. Environmental Modelling \& Software 2019, 119, 285-304, https://doi.org/10.1016/j.envsoft.2019.06.014.

28. Székács, A.; Mörtl, M.; Darvas, B. Monitoring pesticide residues in surface and ground water in Hungary: surveys in 1990-2015. Journal of Chemistry 2015, 2015, https://doi.org/10.1155/2015/717948.

29. Chowdhury, M.; Razzaque, M.; Khan, M. Chlorinated pesticide residue status in tomato, potato and carrot. Journal of Experimental Sciences 2011, 2, 1-5.

30. Fosu-Mensah, B.Y.; Okoffo, E.D.; Mensah, M. Synthetic pyrethroids pesticide residues in soils and drinking water sources from cocoa farms in Ghana. Environment and Pollution 2016, 5, http://dx.doi.org/10.5539/ep.v5n1p60.

31. Abedi-Koupai, J.; Nasri, Z.; Talebi, K.; Mamanpoush, A.; Mousavi, S. Investigation of Zayandehrud water pollution by diazinon and its assimilative capacity. Journal of Science and Technology of Agriculture and Natural Resources 2011, 15, 430-436,

32. Shayeghi, M.; Khoobdel, M.; Vatandoost, H. Determination of organophosphorus insecticides (malathion and diazinon) residue in the drinking water. Pakistan journal of biological sciences: PJBS 2007, 10, 29002904, https://doi.org/10.3923/pjbs.2007.2900.2904.

33. Kent, R.; Belitz, K.; Altmann, A.J.; Wright, M.T.; Mendez, G.O. Occurrence and distribution of pesticide compounds in surface water of the Santa Ana basin, California, 1998-2001. U. S. Geological Survey: 2005.

34. Zhou, R.; Zhu, L.; Yang, K.; Chen, Y. Distribution of organochlorine pesticides in surface water and sediments from Qiantang River, East China. Journal of hazardous materials 2006, 137, 68-75, https://doi.org/10.1016/j.jhazmat.2006.02.005. 
35. Abedi J, N.Z., Talebi Kh, Maman posh A, Mosavai F. Study of chemical quality and contamination of Zayandehrood water upstream of diazinon and its self-purification potential. Journal of Agricultural Science and Technology, Natural Resources, Water and Soil Sciences 2012, 56, 1-19.

36. Aqil, M.; Kita, I.; Yano, A.; Nishiyama, S. A comparative study of artificial neural networks and neurofuzzy in continuous modeling of the daily and hourly behaviour of runoff. Journal of hydrology 2007, 337, 22-34, https://doi.org/10.1016/j.jhydrol.2007.01.013.

37. Hecht-Nielsen, R. Kolmogorov's mapping neural network existence theorem. In: Proceedings of Proceedings of the international conference on Neural Networks. 1987; pp. 11-14.

38. Khataee, A.; Dehghan, G.; Ebadi, A.; Zarei, M.; Pourhassan, M. Biological treatment of a dye solution by Macroalgae Chara sp.: Effect of operational parameters, intermediates identification and artificial neural network modeling. Bioresource technology 2010, 101, 2252-2258, https://doi.org/10.1016/j.biortech.2009.11.079.

39. Mjalli, F.S.; Al-Asheh, S.; Alfadala, H. Use of artificial neural network black-box modeling for the prediction of wastewater treatment plants performance. Journal of Environmental Management 2007, 83, 329-338, https://doi.org/10.1016/j.jenvman.2006.03.004.

40. Vijayan, A.; Mohan, G. Prediction of Effluent Treatment Plant Performance in a Diary Industry Using Artificial Neural Network Technique. J Civil Environ Eng 2016, 6.

41. Ye, Q.; Yang, X.; Chen, C.; Wang, J. River water quality parameters prediction method based on LSTMRNN model. In: Proceedings of 2019 Chinese Control And Decision Conference (CCDC). 2019; pp. 30243028, https://doi.org/10.1109/CCDC.2019.8832885.

42. Pu, F.; Ding, C.; Chao, Z.; Yu, Y.; Xu, X. Water-quality classification of inland lakes using Landsat8 images by convolutional neural networks. Remote Sensing 2019, 11, https://doi.org/10.3390/rs11141674. 